\title{
Influence of Wasting and Underweight on Malaria Status among Ethiopian Children Aged 6-59 Months: A Facility Based Case Control Study
}

Hamid Yimam Hassen ${ }^{1,{ }^{*}}$ and Jemal Haidar $\mathrm{Ali}^{2}$

${ }^{1}$ School of Public Health, College of health science, Mizan-Tepi University, Ethiopia

${ }^{2}$ School of Public Health, Addis Ababa University, Ethiopia

"Corresponding author: Hamid Yimam Hassen, Lecturer, Mizan-Tepi University, Department of Public Health, 7, JM street, Mizan, Teferi, SNNPR, Ethiopia, Tel: +251 913 685693; Mobile: +251922 335552; E-mail: abdulhamidy71@gmail.com

Rec date: Apr 23, 2015 Acc date: Jun 19, 2015 Pub date: June 25, 2015

Copyright: ( 2015 Hassen HY, et al. This is an open-access article distributed under the terms of the Creative Commons Attribution License, which permits unrestricted use, distribution, and reproduction in any medium, provided the original author and source are credited.

\begin{abstract}
Background: Malaria and under-nutrition are among the major causes of childhood mortality in Sub-Saharan Africa including Ethiopia. Although the synergistic relationship of malnutrition and infection are widely documented, the influence of under-nutrition on malaria attack is controversial. This study has addressed the contributory effect of wasting and underweight on malaria status of children

Methodology: An unmatched case control study was employed to assess the influence of wasting and underweight on malaria among children in Ethiopia. A total of 621 sampled children were enrolled and allocated proportionally across the six randomly selected health centers. Children with confirmed malaria were enrolled as cases and for every confirmed malaria case; three controls that visited the facility for fever other than malaria were interviewed based on their order of visiting. Clinical data, anthropometric measurements and blood film was taken by trained personnel. The anthropometric data were converted into nutritional indices using the WHO Anthro software version 3.2.2 and exported to SPSS version 21 for cleaning and further analysis.
\end{abstract}

Result: The overall wasting was significantly associated with confirmed malaria cases. The odds of developing malaria was 2.4 times more among wasted than non-wasted children ( $\mathrm{AOR}=2.440 ; 95 \% \mathrm{Cl}=1.146$ to 5.197 ); and 1.7 times more among underweight children than the referent group ( $A O R=1.69 ; 95 \% \mathrm{Cl}=1.11$ to 2.9$)$.

Conclusion: Being wasted and underweight contributed to the magnitude of malaria and affected the health and nutrition related response. Therefore, integration of nutrition surveillance with malaria control program is essential

Keywords: Unmatched case control study; Children; Wasting; Underweight; Malaria; Integration; Ethiopia

\section{Introduction}

Nutritional status is considered to be one of the major determinants of host immunity to infection [1-3]. It is estimated that two third of deaths among under 5 children in the world are related to feeding factors [4]. It remains among the most critical problems facing the majority of the world's poor population, and dominates the health of the world's poorest nations [5]. About $30.0 \%$ of human population in the developing world are currently suffering from one or more of different forms of malnutrition [6,7]. Globally, 52 million children under 5 years of age were moderately or severely wasted of which more than 5.0\%, suffered from severe wasting in 2011 [7]. Similarly, an estimated 101 million children under 5 years of age were underweight and prevalence in sub-Saharan Africa was 21.0\% [7].

Similarly malaria is a major cause of morbidity and mortality worldwide in general and in most developing countries in particular affecting children below the age of five and pregnant women. Globally, an estimated 3.3 billion people were at risk of malaria with approximately $80.0 \%$ of the cases and $90.0 \%$ of deaths in 2011 occurring in the World Health Organization (WHO) African Region [8].
In Ethiopia both under nutrition and malaria are the leading public health problem. Malnutrition manifested in the form of wasting and underweight reported for the same period were $10.0 \%$ and $29.0 \%$, respectively indicating the magnitude of the problem in the country is serious [9]. An estimated $68.0 \%$ of the population are at risk for malaria and around $80.0 \%$ of the 736 districts in Ethiopia are considered malaria endemic [10]. In 2009/2010, malaria was the leading cause of outpatient visits and health facility admissions, accounting for $14.0 \%$ of outpatient visits and $9.0 \%$ of admissions [10].

Different studies documented the effect of malnutrition on respiratory infections and diarrheal diseases [3,11-13]. But the relationship with malaria is still controversial. Some studies found malnutrition in the form of underweight and wasting increases the risk to have clinical malaria [14-17] while others found no association among different African countries including Ethiopia [18-20] levying some difficulty in managing the issues.

Therefore, the aim of this study was to determine the influence of wasting and underweight on malaria status among Ethiopian children for some program initiatives to be incorporated in the malaria prevention and control programme. 


\section{Methods}

\section{Study area}

The study was conducted in Bahir-Dar special zone situated in the southern shore of Lake Tana and is $564 \mathrm{Km}$ North-west of Addis Ababa, having a latitude and longitude of $11^{\circ} 36^{\prime} \mathrm{N} 37^{\circ} 23^{\prime} \mathrm{E}$ Coordinates: $11^{\circ} 36^{\prime} \mathrm{N} 37^{\circ} 23^{\prime} \mathrm{E}$ and an elevation of 840 meters above sea level. According to Zonal health office report, malaria is endemic in the zone and its transmission is seasonal. The zone has ten health centers ( 3 rural and 7 urban) and of these facilities only 2 rural and 4 urban types of the facilities were purposively selected based on their clients flow and logistics reasons.

\section{Study design and population}

A facility based unmatched case control study was conducted to compare the influence of wasting and underweight on malaria status of children aged 6 to 59 months. All laboratories confirmed malaria cases were included as cases and children with minor upper respiratory tract infection, ear infection, eye infection, minor injury and minor dermal cases were included as controls. Whereas children that had acute lower respiratory tract infection, measles, diarrhoea, severely ill and chronically ill (such as TB, HIV and AIDS etc...) were excluded from the study.

\section{Sample size and sampling procedure}

The required sample size was determined using double proportion formula by considering the magnitude of the two different forms of malnutrition of the Amhara region namely wasting (9.9\%) and underweight $(33.4 \%)$ [9] with level of significance $=0.05$; Marginal error (d) of $=5 \%$; Power of $80.0 \%$, Odds Ratio (OR) of 2.2 and nonresponse rate $=10 \%$. The sample size that yielded the large number from the aforementioned nutritional indices was taken as our working sample since it accommodates all the above scenarios. A total of 621 sample size was estimated and allocated proportionally across the six health centers namely Tis-Abay $(\mathrm{n}=108)$, Meshenti $(\mathrm{n}=108)$ Shinbit $(\mathrm{n}=104)$, Abaymado $(\mathrm{n}=100)$, Bahir Dar $(\mathrm{n}=104)$, and Han $(\mathrm{n}=97)$. All children who had confirmed malaria were enrolled as cases until the required sample size for the respective health centers were reached. For every confirmed malaria case, three controls that visited the facility and fulfilled the inclusion criteria were interviewed randomly based on their order of visiting.

\section{Data collection}

Structured questionnaire, anthropometric equipment (weight scale, stadio-metre), digital thermometer and laboratory equipment were used to collect the required data.

The important variables included in the questionnaire were sociodemographic, clinical, anthropometric and laboratory data. Twelve data collectors fluent in the local languages of the study zone (two clinical nurses from each health centers) and two supervisors with relevant experience were recruited and trained for two days on the method of the data collection. The training addressed issues such as the content of the questionnaire, basic interviewing skills, filling out of the questionnaire and anthropometric measurements.

Weight was measured in kilogram without shoes using a digital bath scale with good precision and recorded to the nearest 100 grams. During weight measurement, the scale was repeatedly checked for accuracy against a known weight. Height/length was taken barefooted in centimeter using stadio-metre. A vertical tape fixed perpendicular to the ground on the wall or recumbent length measurements tape fixed for children under 2 years of age was used as the scale and was recorded to the nearest $1 \mathrm{~cm}$.

Clinical information that included illnesses in the preceding 2 weeks and type of treatments received were assessed by trained underfive Out Patient Diagnosis (OPD) staffs of the respective health centers. Edema was checked by grasping both feet with thumbs on the top of the feet. Pressing thumbs gently for $3 \mathrm{sec}$ or count 10 102, 103 if there was no stop watch and pit (dent) remains in both feet after lifting the hand, the child was considered as having nutritional edema. Axillary Temperature was also measured using Digital thermometer two times and the average of them was taken.

Finger prick following aseptic techniques was done on all subjects to prepare thick and thin films for confirmation of malaria parasite, in the field and stained with Giemsa of the respective health centers. Each slide was read by senior laboratory technicians who had participated during the training. Absence of malaria parasite in 200 high power ocular fields of the thick film was considered as negative.

\section{Data processing and analysis}

Data collected in the health centers were checked for completeness, coded, and entered using Epi-Info version 3.5.4 then exported to SPSS version 21.0 for cleaning and analysis. For computing the nutritional indices, the data were exported to WHO Anthro statistical package version 3.2.2. Children were classified as wasted when the Weight-forHeight Z-scores (WHZ) fall below minus two. Similarly children classified as underweight if Weight-for-Age Z-scores (WAZ) fall below minus two. Severe wasting and underweight were considered when WHZ and WAZ were below minus three Z-score, respectively. Undernutrition was defined as the presence of either of the two indices below minus two Z-score.

The results are presented in percentages and graphs where appropriate. Bivariate analysis was employed to examine the associations between socio-demographic variables and undernutrition with malaria and to identify variables for consideration in multivariate analysis. To ascertain the association between the dependent variables and the explanatory variables, simultaneously controlling for the aforementioned explanatory variables, (All sociodemographic characteristics and other covariates associated in bivariate with $\mathrm{p}<0.2$ were used and entered) stepwise logistic regression was applied and Adjusted Odds Ratios (AORs) and confidence intervals (95\% CI) were constituted. Multicollinearity was also checked for WHZ and WAZ using Variance Inflation Factor (VIF) and two different models were applied to manage it. In all analyses, $\mathrm{P}<0.05$ was considered to be statistically significant.

\section{Ethical consideration}

Ethical approval was obtained from the School of Public Health Research Ethics Review Committee of Addis Ababa University, College of Health Sciences; as well as Amhara Regional Health bureau research ethics committee. Officials of each facility were also contacted, and permission was granted to conduct the study. Informed written consent was obtained from each subject for their participation and the right to withdraw from the study at any time was also communicated to all of them. Anti-malarial treatment was also provided for children with confirmed malaria and under-nourished 
Citation: Hassen HY, Ali JH (2015) Influence of Wasting and Underweight on Malaria Status among Ethiopian Children Aged 6-59 Months: A Facility Based Case Control Study. General Med 3: 1000190. doi:10.4172/2327-5146.1000190

Page 3 of 8

children were referred for to nutritional rehabilitation center according to the national guideline.

\section{Results}

Of the total enrolled subject, 607 (155 cases and 466 controls) participated in the study with a response rate of $96.2 \%$ for cases and
98.3\% for controls, respectively. In both groups, housewives were predominant and less than half had no formal education. The average household members were 4.7 and 5.4 for cases and controls, respectively. Less than a quarter were earning above 2000 Ethiopian Birr (ETB) and urban residents constituted more than half in both groups (Table 1).

\begin{tabular}{|c|c|c|}
\hline \multirow[t]{2}{*}{ Characteristics } & Cases & Controls \\
\hline & $N=149$ & $\mathrm{~N}=458$ \\
\hline \multicolumn{3}{|l|}{ Age (in years) } \\
\hline $20-29$ & $3(2.0 \%)$ & $39(8.5 \%)$ \\
\hline 30-39 & $43(28.9 \%)$ & $200(43.7 \%)$ \\
\hline 40- 49 & $75(50.3 \%)$ & $163(35.6 \%)$ \\
\hline$\geq 50$ & $25(16.8 \%)$ & $52(11.4 \%)$ \\
\hline \multicolumn{3}{|l|}{ Sex } \\
\hline Male & $20(13.4 \%)$ & $74(16.2 \%)$ \\
\hline Female & $129(86.6 \%)$ & $384(83.8 \%)$ \\
\hline \multicolumn{3}{|l|}{ Marital Status } \\
\hline Single & $129(86.6 \%)$ & $414(90.4 \%)$ \\
\hline Divorced & $1(0.7 \%)$ & $4(0.9 \%)$ \\
\hline Widowed & $11(7.4 \%)$ & $28(6.1 \%)$ \\
\hline Separated & $1(0.7 \%)$ & $12(2.6 \%)$ \\
\hline Occupation & $7(4.7)$ & $0(0.0)$ \\
\hline Farmer & $72(48.3 \%)$ & $223(48.7 \%)$ \\
\hline Daily laborer & $43(28.9 \%)$ & $161(35.2 \%)$ \\
\hline Employer & $18(12.1 \%)$ & $23(5.0 \%)$ \\
\hline Merchant & $8(5.4 \%)$ & $45(9.8 \%)$ \\
\hline Other & $7(4.7 \%)$ & $6(1.3 \%)$ \\
\hline Educational level of the respondent & $1(0.7 \%)$ & $0(0 \%)$ \\
\hline Read and write & $73(49.0 \%)$ & $170(37.1 \%)$ \\
\hline Primary (grade 1-8) & $19(12.8 \%)$ & $53(11.6 \%)$ \\
\hline Secondary (grade 9-12) & $25(16.8 \%)$ & $56(12.2 \%)$ \\
\hline 12 and above & $20(13.4 \%)$ & $107(23.4 \%)$ \\
\hline Household Members & $12(8.0 \%)$ & $72(15.7 \%)$ \\
\hline 3-4 & $5(3.4 \%)$ & $19(4.1 \%)$ \\
\hline$\geq 5$ & $75(50.3 \%)$ & $158(34.5 \%)$ \\
\hline Mean (SD) & $69(46.3)$ & $281(61.4 \%)$ \\
\hline \multicolumn{3}{|l|}{ Monthly family income(ETH) } \\
\hline 500-999 & $4.7(1.80)$ & $5.4(2.15)$ \\
\hline
\end{tabular}


Citation: Hassen HY, Ali JH (2015) Influence of Wasting and Underweight on Malaria Status among Ethiopian Children Aged 6-59 Months: A Facility Based Case Control Study. General Med 3: 1000190. doi:10.4172/2327-5146.1000190

Page 4 of 8

\begin{tabular}{|l|l|l|}
\hline $1000-1999$ & $39(26.2 \%)$ & $79(17.2 \%)$ \\
\hline$\geq 2000$ & $36(24.2 \%)$ & $181(39.5 \%)$ \\
\hline Mean (SD) & $53(35.6 \%)$ & $133(29.0 \%)$ \\
\hline Residence & $21(14.1 \%)$ & $65(14.2 \%)$ \\
\hline Rural & $1106.3(820.1)$ & $1026.9(778.5)$ \\
\hline Wall of house & $62(41.6 \%)$ & $66(14.4 \%)$ \\
\hline Concrete & $119(79.9 \%)$ & $344(75.1 \%)$ \\
\hline Others & $21(14.1 \%)$ & $99(21.6 \%)$ \\
\hline Parent of the child & $9(6.0 \%)$ & $15(3.3 \%)$ \\
\hline Alive & $130(87.2 \%)$ & $429(93.7 \%)$ \\
\hline Died & $19(12.8 \%)$ & $29(6.3 \%)$ \\
\hline Total & $149(100 \%)$ & $458(100 \%)$ \\
\hline
\end{tabular}

Table 1: Socio-demographic characteristics of respondents by study groups, Bahir Dar special zone, Ethiopia, 2014.

\section{Measures of children's nutritional status and socio- demographic characteristics}

Table 2 displays various child characteristic by the study groups. As shown, more than half $(58.4 \%)$ of cases and $(51.5 \%)$ of controls were males. The mean age was 27.5 and 32.2 months for cases and controls, respectively and the difference noted was significant $(\mathrm{p}=0.04)$. The mean temperature (in degree Celsius) of cases and controls was 37.8 $(+0.8)$ and $36.4(+0.7)$, respectively. Overall, the proportion of wasting was higher among cases (12.1\%) than controls $(5.7 \%)$ and the difference was significant $(\mathrm{p}=0.01)$. When wasting was further disaggregated by severity, both severe and moderate wasting was higher among cases than controls though the difference was only significant among those who had moderate wasting $(\mathrm{p}=0.04)$. Likewise, underweight was significantly higher among cases $(34.2 \%)$ than the control groups $(32.3 \%)$. When underweight was further classified by severity, malaria was higher among both severe and moderate underweight children. However, only moderate underweight was statistically significant $(\mathrm{p}=0.01)$.

\begin{tabular}{|l|l|l|l|}
\hline \multirow{2}{*}{ Characteristics } & Cases & Controls & \multirow{2}{*}{ P - value } \\
\cline { 2 - 3 } & N=149 & N=458 & \\
\hline Sex & \multicolumn{3}{|l}{} \\
\hline Male & $87(58.4 \%)$ & $236(51.5 \%)$ & 0.14 \\
\hline Female & $62(41.6 \%)$ & $222(48.5 \%)$ & \\
\hline Child age (in months) & \multicolumn{2}{|l}{} \\
\hline Jun-24 & $70(47.0 \%)$ & $173(37.8 \%)$ & 0.04 \\
\hline $24-59$ & $79(53.0 \%)$ & $285(62.2 \%)$ & \\
\hline Mean age ( \pm SD) & $27.5( \pm 12.9)$ & $32.2( \pm 16.3)$ & 0.01 \\
\hline Mean Temperature $( \pm S D)$ & $37.8( \pm 0.8)$ & $36.4( \pm 0.7)$ & 0.01 \\
\hline
\end{tabular}

\begin{tabular}{|l|l|l|l|}
\hline Wasting (overall) & $18(12.1 \%)$ & $26(5.7 \%)$ & 0.01 \\
\hline Severe wasting & $7(4.7 \%)$ & $10(2.2 \%)$ & 0.08 \\
\hline Moderate wasting & $11(7.4 \%)$ & $16(3.5 \%)$ & 0.04 \\
\hline Normal & $131(87.9 \%)$ & $432(94.3 \%)$ & \\
\hline Underweight (overall) & $51(34.2 \%)$ & $102(32.3 \%)$ & 0.01 \\
\hline Severe underweight & $14(9.4 \%)$ & $31(6.8 \%)$ & 0.07 \\
\hline Moderate underweight & $37(24.8 \%)$ & $71(15.5 \%)$ & 0.01 \\
\hline Normal & $98(65.8 \%)$ & $356(77.7 \%)$ & \\
\hline Total & $149(100 \%)$ & $458(100 \%)$ & \\
\hline
\end{tabular}

Table 2: Children characteristics by study groups at Bahir Dar special zone, Ethiopia, June, 2014.

\section{The relationship of wasting, underweight and socio- demographic variables with malaria}

As shown in Table 3 , the overall wasting was significantly associated with confirmed malaria cases. Overall, the odds of developing malaria was 2.4 times more among wasted than non-wasted children (Adjusted Odds Ratio $(\mathrm{AOR})=2.440 ; 95 \% \quad \mathrm{CI}=1.146$ to 5.197). Likewise, the odds of developing malaria was 1.7 times more among underweight children than the referent group ( $\mathrm{AOR}=1.69$; $95 \% \mathrm{CI}=1.11$ to 2.9 ) (Table 4 ).

Long lasting insecticide treated net (LLIN) utilization, indoor residual spray, Place of residence and sex of the child, were other important variables that were significantly associated with occurrence of malaria after controlling for the confounding effects in the multivariate model. 
Citation: Hassen HY, Ali JH (2015) Influence of Wasting and Underweight on Malaria Status among Ethiopian Children Aged 6-59 Months: A Facility Based Case Control Study. General Med 3: 1000190. doi:10.4172/2327-5146.1000190

Page 5 of 8

\begin{tabular}{|c|c|c|c|c|}
\hline Variable & Cases & Controls & Crude OR $(95 \% \mathrm{Cl})$ & Adjusted OR $(95 \% \mathrm{Cl})$ \\
\hline \multicolumn{5}{|l|}{ Wasting } \\
\hline Yes & $18(12.1 \%)$ & $26(5.7 \%)$ & $2.283(1.214,4.295)$ & $2.440(1.146,5.197)^{\star}$ \\
\hline No & $131(87.9 \%)$ & $432(94.3 \%)$ & 1 & 1 \\
\hline \multicolumn{5}{|l|}{ Residence } \\
\hline Rural & $62(41.6 \%)$ & $66(14.4 \%)$ & $4.233(2.789,6.424)$ & $2.349(1.387,3.979)^{*}$ \\
\hline Urban & $87(58.4 \%)$ & $392(85.6 \%)$ & 1 & 1 \\
\hline \multicolumn{5}{|l|}{ Sex } \\
\hline Male & $87(58.4 \%)$ & $236(51.5 \%)$ & $1.320(0.908,1.918)$ & $1.884(1.192 .980)^{*}$ \\
\hline Female & $62(41.6)$ & $222(48.5 \%)$ & 1 & 1 \\
\hline \multicolumn{5}{|l|}{ Child age } \\
\hline $6-24$ & $70(47.0 \%)$ & $173(37.8 \%)$ & $0.685(0.472,0.995)$ & $0.928(0.587,1.466)$ \\
\hline 24-59 & $79(53.0 \%)$ & $285(62.2 \%)$ & 1 & 1 \\
\hline \multicolumn{5}{|c|}{ Sleep under LLIN a night preceding } \\
\hline Yes & $43(28.9 \%)$ & $303(66.2 \%)$ & $0.208(0.139,0.311)$ & $0.204(0.128,0.325)^{\star}$ \\
\hline No & $106(71.1 \%)$ & $155(33.8 \%)$ & 1 & 1 \\
\hline \multicolumn{5}{|c|}{ Indoor residual spray within last 12 month } \\
\hline Yes & $63(42.3 \%)$ & $338(73.8)$ & $0.260(0.177,0.383)$ & $0.257(0.154,0.430)^{\star}$ \\
\hline No & $86(57.7 \%)$ & $120(26.2)$ & 1 & 1 \\
\hline \multicolumn{5}{|l|}{ Wall of house } \\
\hline Mud and wood & $128(85.9 \%)$ & $359(78.4 \%)$ & $1.681(1.007,2.805)$ & $1.213(0.896,1.842)$ \\
\hline Concrete & $21(14.1 \%)$ & $99(21.6 \%)$ & 1 & \\
\hline \multicolumn{5}{|c|}{ Educational level of respondent } \\
\hline Cannot read and write & $73(49.0 \%)$ & $170(37.1 \%)$ & 1 & 1 \\
\hline Read and write & $19(12.8 \%)$ & $53(11.6 \%)$ & $0.835(0.462,1.508)$ & $0.974(0.501 .896)$ \\
\hline Grade 1-12 & $45(30.2 \%)$ & $163(35.6 \%)$ & $0.643(0.419,0.987)$ & $0.687(0.406,1.161)$ \\
\hline Above 12 & $12(8.1 \%)$ & $72(15.7 \%)$ & $0.388(0.199,0.758)$ & $0.300(0.114,0.785)^{\star}$ \\
\hline \multicolumn{5}{|c|}{ Occupation of respondent } \\
\hline House wife & $72(48.3 \%)$ & $223(48.7 \%)$ & 1 & 1 \\
\hline Farmer & $43(28.9 \%)$ & $161(35.2 \%)$ & $\begin{array}{l}0.827(0.539,1.270) 2.777 \text { (1.536, } \\
5.021)\end{array}$ & $0.950(0.569,1.585)$ \\
\hline Merchant and other & $26(17.4 \%)$ & $29(6.3 \%)$ & $0.551(0.248,1.222)$ & $2.820(1.308,6.083)^{\star}$ \\
\hline Employer & $8(5.4 \%)$ & $45(9.8 \%)$ & & $0.492(0.152,1.596)$ \\
\hline
\end{tabular}

Table 3: Association between wasting and confirmed malaria in pre-school children at Bahir Dar special zone, 2014. Predictors with ${ }^{*}$ were significantly associated factors controlled for other variables in the table $(\mathrm{P}<0.05)$.

\begin{tabular}{|l|l|l|l|l|}
\hline Variable & Cases & Controls & Crude OR $(95 \% \mathrm{Cl})$ & Adjusted OR $(95 \% \mathrm{Cl})$ \\
\hline
\end{tabular}


Citation: Hassen HY, Ali JH (2015) Influence of Wasting and Underweight on Malaria Status among Ethiopian Children Aged 6-59 Months: A Facility Based Case Control Study. General Med 3: 1000190. doi:10.4172/2327-5146.1000190

Page 6 of 8

\begin{tabular}{|c|c|c|c|c|}
\hline \multicolumn{5}{|l|}{ Underweight } \\
\hline Yes & $51(34.2 \%)$ & $102(22.3 \%)$ & $1.816(1.213,2.720)$ & $1.690(1.112,2.903)^{*}$ \\
\hline No & $98(65.8 \%)$ & $356(77.7 \%)$ & 1 & \\
\hline \multicolumn{5}{|l|}{ Residence } \\
\hline Rural & $62(41.6 \%)$ & $66(14.4 \%)$ & $4.233(2.789,6.424)$ & $2.009(1.108,3.662)^{\star}$ \\
\hline Urban & $87(58.4 \%)$ & $392(85.6 \%)$ & 1 & 1 \\
\hline \multicolumn{5}{|l|}{ Sex } \\
\hline Male & $87(58.4 \%)$ & $236(51.5 \%)$ & $1.320(0.908,1.918)$ & $1.681(1.022 .690)^{*}$ \\
\hline Female & $62(41.6)$ & $222(48.5 \%)$ & 1 & 1 \\
\hline \multicolumn{5}{|l|}{ Child age } \\
\hline $6-24$ & $70(47.0 \%)$ & $173(37.8 \%)$ & $0.685(0.472,0.995)$ & $1.328(0.980,1.714)$ \\
\hline $24-59$ & $79(53.0 \%)$ & $285(62.2 \%)$ & 1 & 1 \\
\hline \multicolumn{5}{|c|}{ Sleep under LLIN last night } \\
\hline Yes & $43(28.9 \%)$ & $303(66.2 \%)$ & $0.208(0.139,0.311)$ & $0.372(0.168,0.495)^{*}$ \\
\hline No & $106(71.1 \%)$ & $155(33.8 \%)$ & 1 & 1 \\
\hline \multicolumn{5}{|c|}{ Indoor residual spray within last 12 month } \\
\hline Yes & $63(42.3 \%)$ & $338(73.8)$ & $0.260(0.177,0.383)$ & $0.457(0.304,0.610)^{*}$ \\
\hline No & $86(57.7 \%)$ & $120(26.2)$ & 1 & 1 \\
\hline \multicolumn{5}{|l|}{ Wall of house } \\
\hline Mud and wood & $128(85.9 \%)$ & $359(78.4 \%)$ & $1.681(1.007,2.805)$ & $1.103(0.791 .794)$ \\
\hline Concrete & $21(14.1 \%)$ & $99(21.6 \%)$ & 1 & \\
\hline \multicolumn{5}{|c|}{ Educational level of respondent } \\
\hline Cannot read and write & $73(49.0 \%)$ & $170(37.1 \%)$ & 1 & 1 \\
\hline Read and write & $19(12.8 \%)$ & $53(11.6 \%)$ & $0.835(0.462,1.508)$ & $0.804(0.601 .916)$ \\
\hline Grade 1-12 & $45(30.2 \%)$ & $163(35.6 \%)$ & $0.643(0.419,0.987)$ & $0.708(0.506,1.260)$ \\
\hline Above 12 & $12(8.1 \%)$ & $72(15.7 \%)$ & $0.388(0.199,0.758)$ & $0.608(0.414,1.085)$ \\
\hline \multicolumn{5}{|c|}{ Occupation of respondent } \\
\hline House wife & $72(48.3 \%)$ & $223(48.7 \%)$ & 1 & 1 \\
\hline Farmer & $43(28.9 \%)$ & $161(35.2 \%)$ & $0.827(0.539,1.270)$ & $0.852(0.420,1.481)$ \\
\hline Merchant and other & $26(17.4 \%)$ & $29(6.3 \%)$ & $2.777(1.536,5.021)$ & $1.820(0.918,5.460)$ \\
\hline Employer & $8(5.4 \%)$ & $45(9.8 \%)$ & $0.551(0.248,1.222)$ & $0.602(0.355,1.737)$ \\
\hline
\end{tabular}

Table 4: Association between underweight and confirmed malaria in pre-school children at Bahir Dar special zone, 2014. Predictors with '*' were significantly associated factors controlled for other variables in the table $(\mathrm{P}<0.05)$.

\section{Discussion}

This facility based case control study attempted to find out the influence of wasting and underweight on malaria status of children which are important public health significance in the country as well as in many developing countries. The information obtained is important for some program initiatives to be incorporated in the malaria and undernutrition prevention and control approach. The available evidences on the relationship between malaria and undernutrition in the form of wasting and underweight are debatable. But, the present study had identified the assertion that wasted and underweight children are at higher risk to contract malaria than well- 
nourished children. As a result, the odds of having confirmed malaria was 2.4 times higher among wasted than non-wasted children which is coherent with a study conducted in Vanuatu that followed a much larger group of children $(\mathrm{n}=511)$ and found that Plasmodium Vivax malaria during the six-month period before assessment was strongly associated with acute malnutrition [21]. Similarly a study conducted in Southeast Asia found that wasted children have higher odds of malaria specifically to $P$. falciparum [22]. On the other hand, an observational follow-up study in a rural area of Senegal indicated that wasted children were at lower risk of experiencing at least one subsequent clinical malaria attack $(\mathrm{OR}=0.33$; 95\% $\mathrm{CI}=0.13-0.81)$ [18]. But the study focused on subsequent clinical malaria attack acquired immunity could be developed and the prevalence of wasting was low due to seasonal variation. Another study conducted in Western Ethiopia show that there was no statistically significant association between wasting and malaria status of children (19) but the prevalence of malaria was very low making the comparison difficult. On the other hand, the higher odds of malaria among wasted children is supported by an immunologic study in Papua New Guinea and Ghana reported that humoral responses and anti-malarial immunoglobulin to malarial antigens have been found to be low in wasted children, suggesting that wasting is a risk for malaria $[17,23]$.

Regarding underweight, the odds of having confirmed malaria case was 1.7 times higher among underweight children than their counterparts and the finding is in line with a study in Nigeria which showed that underweight were significantly associated with malaria attack in children [24]. Similarly a study in Sudan indicated that malaria was more often in malnourished than in adequately nourished children [25]. According to WHO's Comparative Risk Assessment project, children who were moderately to severely underweight had an increased risk of acquiring clinical malaria than better nourished children though the difference is not significant $(1.395 \%$ CI: 0.92-1.88) [26]. The higher odds of confirmed malaria among underweight children could be through a reduction in the function of the immune system due to reduction in T lymphocytes, impairment of antibody formation, decreased complement formation, and atrophy of thymus and other lymphoid tissues [3]. Similar explanation was forwarded by a study in northern Guinea which used large sample size comprising of 4000 children [23]. In contrast to the present findings, the Kenyan, Gambia and Uganda studies had reported no relationship between baseline nutritional status and subsequent incidence of malaria [27-29]. The discrepancy noted with the present study could be explained by the difference in the type of malaria transmission whether seasonal or holo-endemic.

Other important factors that had strong association with malaria attack were LLIN utilization for children during sleeping, used indoor residual spray (IRS) in the last 12 months, sex of the children and their place of residence.

The strength of the study is that it compared cases and controls with appropriate sample size, used laboratory for confirmation for malaria diagnosis which decreased the subjectivity of diagnosis/bias and inclusion of anthropometric measurements. Some of the limitations of this study was did not assess the level of micronutrients status, anemia and the level of parasitaemia which might have impact on malaria morbidity. In addition, it would have been better if the controls were matched from the community. It didn't clearly identify the temporal relationship of malaria with acute under-nutrition as well.
In conclusion, the study substantiated some previous findings that under-nutrition in the form of wasting and underweight are associated with malaria attack. It is recommended that health offices and NGOs operating in malaria endemic area should give special attention for children with under nutrition and distribute LLIN for households and creates awareness on the importance of other preventive measures addressing the aforementioned predictors including the integration of malaria and essential nutrition actions. Further large scale research with more biochemical tests might be helpful to answer some of the limitations felt in this study.

\section{Authors Contributions}

HHY designed the study, collected the data including the analysis and drafted the manuscript. JAH contributed in the data interpretation and the write up of the manuscript for intellectual content. All authors read, critically revised and approved the final manuscript.

\section{Acknowledgement}

The school ethics committee including all the staff from Bahir Dar health offices, respective health centers, and the municipality are duly acknowledged. This work would not have reached its present state without the unreserved participation of the respondents and the support rendered of our families.

\section{References}

1. Enwonwu CO (2006) Complex interactions between malnutrition, infection and immunity: relevance to HIV/AIDS infection. Nigerian Journal of Clinical and Biomedical Research 1: 6-4.

2. Katona P, Katona-Apte J (2008) The interaction between nutrition and infection. Clin Infect Dis 46: 1582-1588.

3. Scrimshaw NS, SanGiovanni JP (1997) Synergism of nutrition, infection, and immunity: an overview. Am J Clin Nutr 66: 464S-477S.

4. UNICEF and WHO (2007) Progress for Children: A World Fit for Children statistical review 6: 19-24.

5. United Nations Administrative Committee on Coordination and Standing Committee on Nutrition, Fourth Report on the World Nutrition. Geneva. ACC/SCN, 2005.

6. FAO (2012) Report of Food and Agricultural Organization.

7. UNICEF, Improving child nutrition: The achievable imperatives for global progress. World nutrition report, 2013.

8. WHO (2012) Global Malaria Programme; World malaria report.

9. CSA (2012) Ethiopian Demographic and Health Survey.

10. EHNRI and partners, Ethiopian Malaria indicator survey report 2011.

11. Chisti MJ (2010) Clinical and laboratory features of radiologic pneumonia in severely malnourished infants attending an urban diarrhea treatment center in Bangladesh. Pediatric Infect Dis J 29: 174-177.

12. Cunningham-Rundles S, McNeeley DF, Moon A (2005) Mechanisms of nutrient modulation of the immune response. J Allergy Clin Immunol 115: 1119-1128.

13. Roth DE (2008) Acute lower respiratory infections in childhood: opportunities for reducing the global burden through nutritional interventions. Bull World Health Organ 86: 356-364.

14. Deen JL, Walraven GE, von Seidlein L (2002) Increased risk for malaria in chronically malnourished children under 5 years of age in rural Gambia. J Trop Pediatr 48: 78-83.

15. Friedman JF, Kwena AM, Mirel LB, Kariuki SK, Terlouw DJ, et al. (2005) Malaria and nutritional status among pre-school children: results from cross-sectional surveys in western Kenya. Am J Trop Med Hyg 73: 698-704. 
Citation: Hassen HY, Ali JH (2015) Influence of Wasting and Underweight on Malaria Status among Ethiopian Children Aged 6-59 Months: A Facility Based Case Control Study. General Med 3: 1000190. doi:10.4172/2327-5146.1000190

Page 8 of 8

16. Verhoef H, West CE, Veenemans J, Beguin Y, Kok FJ (2002) Stunting may determine the severity of malaria-associated anemia in African children. Pediatrics 110: e48.

17. Fillol F, Sarr JB, Boulanger D, Cisse B, Sokhna C, et al. (2009) Impact of child malnutrition on the specific anti-Plasmodium falciparum antibody response. Malar J 8: 116.

18. Fillol F, Cournil A, Boulanger D, Cissé B, Sokhna C, et al. (2009) Influence of wasting and stunting at the onset of the rainy season on subsequent malaria morbidity among rural preschool children in Senegal. Am J Trop Med Hyg 80: 202-208.

19. Crookston BT, Alder SC, Boakye I, Merrill RM, Amuasi JH, et al. (2010) Exploring the relationship between chronic undernutrition and asymptomatic malaria in Ghanaian children. Malar J 9: 39.

20. Deribew A, Alemseged F, Tessema F, Sena L, Birhanu Z, et al. (2010) Malaria and under-nutrition: a community based study among underfive children at risk of malaria, south-west Ethiopia. PLoS One 5: e10775.

21. Williams TN, Maitland K, Phelps L, Bennett S, Peto TE, et al. (1997) Plasmodium vivax: a cause of malnutrition in young children. QJM 90: 751-757.

22. Takakura M (2001) The Relationship Between Anthropometric Indicators Of Nutritional Status And Malaria Infection Among Youths in Khammouane Povince, LAO PDR. South East Asian J Trop Med Public Health 32: 262-267.

23. Genton B, Al-Yaman F, Ginny M, Taraika J, Alpers MP (1998) Relation of anthropometry to malaria morbidity and immunity in Papua New Guinean children. Am J Clin Nutr 68: 734-741.
24. Jeremiah ZA, Uko EK (2007) Childhood asymptomatic malaria and nutritional status among Port Harcourt children. East Afr J Public Health 4: 55-58.

25. el Samani FZ, Willett WC, Ware JH (1987) Nutritional and sociodemographic risk indicators of malaria in children under five: a crosssectional study in a Sudanese rural community. J Trop Med Hyg 90: 69-78.

26. Caulfield LE Richard SA, Black RE (2004) Undernutrition as an underlying cause of malaria morbidity and mortality in children less than five years old. Am J Trop Med Hyg 71: 55-63.

27. Nyakeriga AM, Troye-Blomberg M, Chemtai AK, Marsh K, Williams TN (2004) Malaria and nutritional status in children living on the coast of Kenya. Am J Clin Nutr 80: 1604-1610.

28. Snow RW (1997) The relationship between anthropometric measurements and measurements of iron status and susceptibility to malaria in Gambian children. J of Medical Research Council Laboratories Gambia 3: 584-589.

29. Arinaitwe E, Gasasira A, Verret W, Homsy J, Wanzira H, et al. (2012) The association between malnutrition and the incidence of malaria among young HIV-infected and -uninfected Ugandan children: a prospective study. Malar J 11: 90 